\title{
Lessons Learned from the Development of Open Educational Resources at Post-Secondary Level in the Field of Environmental Modelling: An Exploratory Study
}

\author{
Quazi K. Hassan ${ }^{1, *}$, Khan R. Rahaman ${ }^{2}$, Kazi Z. Sumon ${ }^{3}$ and Ashraf Dewan ${ }^{4}$ \\ 1 Department of Geomatics Engineering, Schulich School of Engineering, University of Calgary, \\ 2500 University Dr. NW, Calgary, AB T2N 1N4, Canada \\ 2 School of Urban and Regional Planning, University of Alberta, 116 St. and 85 Ave., Edmonton, \\ AB T6G 2R3, Canada; krahaman@ualberta.ca \\ 3 Department of Chemical and Petroleum Engineering, Schulich School of Engineering, University of Calgary, \\ 2500 University Dr. NW, Calgary, AB T2N 1N4, Canada; kazi.sumon@ucalgary.ca \\ 4 Spatial Sciences Discipline, School of Earth and Planetary Sciences, Curtin University, Kent St, Bentley, \\ WA 6102, Australia; a.dewan@curtin.edu.au \\ * Correspondence: qhassan@ucalgary.ca; Tel.: +1-403-210-9494
}

Received: 29 March 2019; Accepted: 6 May 2019; Published: 13 May 2019

\begin{abstract}
Open educational resources (OER) have become increasingly popular in recent times. Here, the aim was to synthesise the lessons learned through the development of OER materials for a university-level course called "environmental modelling". Consequently, the topics of discussion included: (i) how to choose an appropriate creative commons license; (ii) ways of incorporating materials from other sources, such as publicly available sources, other open access materials, and an author's own published materials if not published under a creative commons license; (iii) the impact of the developed OER in the field of environmental modelling; and (iv) the challenges in developing OER material. Upon developing the materials, we observed the following: (i) students enrolled in the course did not purchase textbooks; (ii) our OER materials ranked as one of the most accessed (i.e., number 7) materials according to the usage data that summed the number of file downloads and item views from PRISM (i.e., the hosting platform maintained by the University of Calgary); (iii) the students learned relatively better as per the data acquired by the University of Calgary's universal student ratings of instruction (USRI) instrument; and (iv) other universities expressed interest in adopting the materials.
\end{abstract}

Keywords: creative commons license; environmental educational materials; OER developmental challenges; OER adaptation; OER adaptation; OER creation

\section{Introduction}

Open education resources (OER) are materials that are openly available for reuse, modification, and sharing that originated in the later part of the twentieth century [1]. In 1994, Wayne Hodgins introduced the term "learning object" to describe any packaged digital resource useful for educational purposes [2,3]. Consequently, the concept of generative learning objects (GLOs) was developed to overcome restrictions that made it difficult to gain full benefits from the use of these generated resources [4]. The term "generative" is understood as a property of the learning content produced and handled either semi-automatically or automatically [5] with the support of some technology. As a result, GLOs have been considered as a leading technology of choice for eLearning support due to their 
potential generativity, adaptability, and scalability [6], as computer-based teaching components are considered an inevitable part of teaching and learning at post-secondary institutions. Many eLearning resources have been developed for specific environments, which restricts them from being in others. Due to this, in order to gain a positive return on investment, it is crucial that these eLearning resources are able to be repurposed, reused, and to be useable on a number of different platforms [7]. Usually a GLO has five major stages: (i) orientation stage; (ii) disclosure of ideas stage; (iii) challenges and restructuring stage; (iv) implementation stage; and (v) looking back stage [8]. In most cases, it is difficult to follow all the mentioned stages. Moreover, the idea has been criticized as it does not include options for the reuse and adaptation of developed materials in light of the pedagogical richness of the learning objects. Additionally, in order to overcome the limitations of the traditional ways of classroom teaching, computer games and interactive engagement through computer simulations have been gaining popularity $[9,10]$. However, the challenges remain in creating new materials that consider the licensing systems with appropriate permissions of materials used in these resources.

As a matter of fact, the term OER was first widely introduced at a United Nations Educational, Scientific, and Cultural Organization (UNESCO) conference in 2000, and it was promoted in the context of providing free access to educational resources on a global scale [11]. Consequently, the wave of OER started to spread when the Massachusetts Institute of Technology (MIT) OpenCourseWare [12] and the Organization for Economic Co-operation and Development (OECD) [13] took initiatives to develop OER in the early twenty-first century. One of the most commonly accredited definitions for the term OER then came along from the OECD report as "digested materials offered freely and openly for educators, students, and self-learners to use and reuse for teaching, learning, and research" [13]. It is worth noting that the resources in the mentioned definition were not limited to content, but comprised three areas [13]:

(i) Learning content: Full courses, courseware, content modules, learning objects, collections, and journals;

(ii) Tools: Software to support the development, use, reuse, and delivery of learning content and materials;

(iii) Implementation resources: Intellectual property licenses to promote open publishing of materials, design principles of best practices, and localize content.

Therefore, OER mainly comprise teaching and learning, software-based tools and services, and licenses that allow open development and reuse of content, tools, and services $[14,15]$.

On a global scale, there is a demand for high-quality OER materials that support the educational resources accessible to stakeholders related to teaching and learning at different geographical locations [16-19]. In this context, it would be worth mentioning some of the prominent OER developments for university-level courses: (i) MIT OpenCourseWare [12] and Rice University's Connexions project [20] in the United States; (ii) BCcampus OpenEd in Canada [21]; and (iii) the Japanese Open Course Ware Consortium [22] that provides access to about 400 courses from its 19 member universities. Moreover, the OpenCourseWare consortium (one of the global networks for open education) is collaborating with more than 200 higher education institutions and associate organizations from around the world to create a broad and deep body of open educational content using a shared model [23]. The mission there was to advance education and empower people worldwide through open courseware. Very recently in 2017, the global health charity, Bill and Melinda Gates Foundation, partnered with the American Association for the Advancement of Science (AAAS) in a yearlong agreement to "expand access to high-quality scientific publishing", which means that the foundation's funded research can be published on open access terms in Science and four other relevant journals [19].

Canada is unique in terms of education, as the federal government has no authority in the education sector, and education is exclusively a provincial responsibility [24]. However, there is a federal program to promote the growth of the open data movement through new open data licensing 
when the federal government funds research projects [25]. The governments of the three western Canadian provinces (i.e., Alberta, British Columbia, and Saskatchewan) have initiated the process of generating OER for post-secondary education in recent years [26]. In Alberta, the University of Calgary (UofC) spent approximately $\$ 13.63$ million to acquire academic resources in the 2015-2016 session that included electronic journals, databases, and other scholarly materials, according to UofC's Libraries and Cultural Resources [27]. Additionally, there is another interesting fact-academics, including the UofC community, produce vast amounts of knowledge and synthesize this in the form of books, peer-reviewed journal articles, conference proceeding papers, reports, etc. However, the publishers sell these to the users (including the UofC community) again and again in the event that we opt to use them to disseminate knowledge from time to time. In the face of the above obstacles, the Canadian Tri-Council consisting of the following three granting agencies: (i) Natural Sciences and Engineering Research Council (NSERC); (ii) Social Sciences and Humanities Research Council (SSHRC); and (iii) Canadian Institutes of Health Research (CIHR), has adopted policies that their grantees should publish in open access platforms so that the generated knowledge is freely available to all the users across the world. Similar steps have also been adopted by the governmental funding agencies of USA, UK, Germany, and Australia $[14,16,28]$. It is worth mentioning that UofC has established an open access author's fund to help stakeholders in the event that they have exhausted all other funding sources [29].

As the concept and activities of openness are clearly evident in many Canadian universities and community colleges (i.e., post-secondary institutions), to introduce OER materials in order to broaden open access and build learning repositories, we have opted to create course materials in the Schulich School of Engineering at the University of Calgary. In doing so, we have generated a series of lecture notes under the umbrella of OER for an environmental modelling course (the course is taught at both graduate and undergraduate level) [30]. These lecture notes are freely accessible through the repository of the University of Calgary called PRISM [31]. In the scope of this paper, the aim was to synthesize the lessons learned from the development of the above-mentioned materials. Specifically, we focused on the following four issues: (i) adoption of an appropriate creative commons license; (ii) ways of incorporating materials from other sources such as publicly available sources, other open access materials, and an author's own published materials if not published under a creative commons license; (iii) the impact of the developed materials in the field of environmental modelling, both in-house and globally; and (iv) the challenges in developing OER material.

\section{Methods}

Our proposed methods consisted of three major components. Those included the following: (i) choosing the appropriate license for the OER materials; (ii) ways of incorporating materials from various resources; and (iii) analysing the impact of the developed OER. All these components are briefly described in the following subsections.

\subsection{Choosing an Appropriate License}

As we intended to develop OER materials, we opted to select a Creative Commons (CC) license that would allow people to copy, adapt, and distribute materials without requesting permission from the resource creator or paying license fees [32]. These licenses do not conflict with the copyright principles; they are a modification to "all rights reserved" copyrights [33]. In the scope of CC licensing, one of the most widely used approaches is the selection of CC BY, which allows anyone who complies with the standard CC terms to use the work for any purpose they wish (e.g., commercial use). In addition, there are several variations of CC BY licensing. For example, Katz [34] assembled the CC BY licensing attributions into three categories: (i) CC BY-No Derivatives (ND), which does not allow the creation of derivative works; (ii) CC BY-Share Alike (SA), which grants full rights to derivative works but requires them to be released under the same license as the original work (if derivative works are distributed, displayed, or performed); and (iii) CC BY-Non Commercial (NC), which grants full rights to derivative works but does not allow them to be used for any commercial purposes. 
Therefore, as academic researchers affiliated with post-secondary institutions, we opted to use the CC BY-NC-SA licensing system so that the generated OER materials could be restricted to use for academic and/or other non-commercial purposes and shared under the original terms and conditions. Similar measures were recommended by MIT OpenCourseWare [12] and the McGill model [11] so that the created/adopted/adapted OER materials could be of use for academic purposes for continuous support towards teaching and learning worldwide.

\subsection{Ways of Incorporating Materials from Various Sources}

Apart from creating the author-owned OER materials, we opted to adopt and/or adapt contents (e.g., mainly figures) from other sources as these would need fewer resources (i.e., human and/or financial). Those included the following: (i) existing CC BY licensed materials; (ii) public domain information/databases; and (iii) authors' own works where the copyright had already been transferred to a publisher. All these cases are briefly discussed in the following subsections.

\subsubsection{Adopting/Adapting from CC BY Licensed Materials}

If any materials were published under one of the CC BY licenses other than CC BY-ND, then we adopted/adapted it with appropriate attributions. Figure 1 is an example of the adoption of a graphic available from Ahmed et al. [35] that was originally published under a CC BY 4.0 license inside a research article. It depicts the wildland-urban interface (WUI), as shown by a dotted yellow line, along with buffer zones at $10 \mathrm{~m}, 30 \mathrm{~m}, 50 \mathrm{~m}, 70 \mathrm{~m}$, and $100 \mathrm{~m}$. In fact, panel (a) in Figure 1 shows an example of areas where forest/plants were removed to protect nearby communities from wildfire. On the other hand, panel (b) in Figure 1 shows an example of a wildland fire-induced vulnerable area, where the existence of the vegetation (reddish color) would favor the forest fire propagation into the communities. Additionally, we adopted many graphics available from Wikipedia, where we used the attribution as: ["Title of the graphics" by Author name from Wikipedia is licensed under license type [e.g., CC BY 3.0]; website].

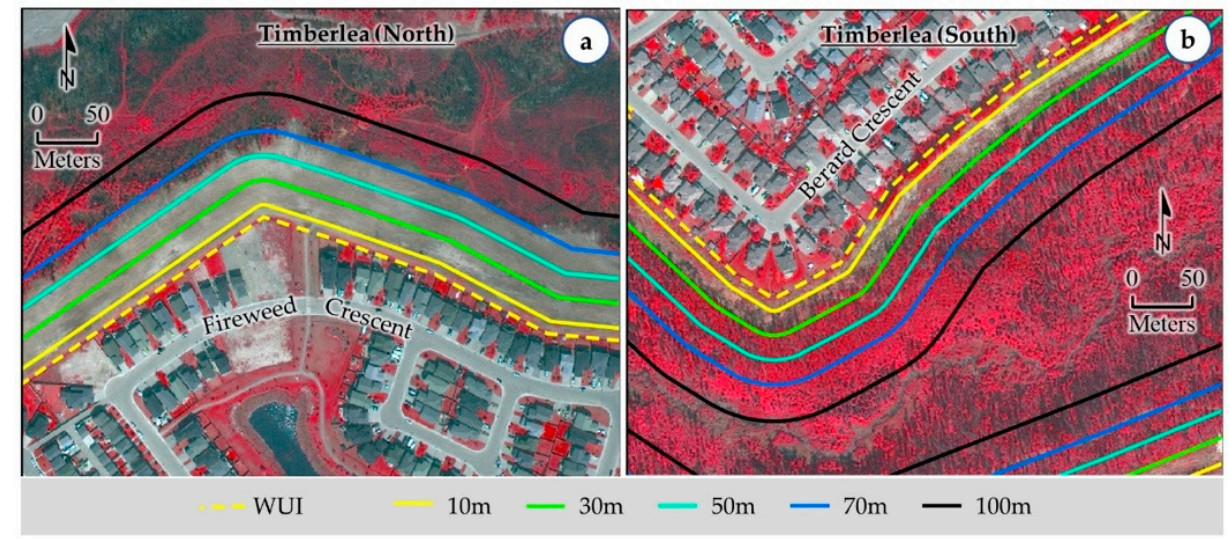

Figure 1. Example of the wildland-urban interface (WUI) and buffer zones around communities of interest that was "adopted from (C)Ahmed, Rahaman, \& Hassan, 2015 and licensed under CC BY 4.0". Panel (a) illustrates an area where authorities removed vegetation from the buffer zones during the fire-event to protect a nearby community; and Panel (b) shows an example of wildland fire-induced vulnerable area.

Figure 2 illustrates the concept of modifying a graphic that was originally published in Hazaymeh and Hassan [36] under a CC BY 4.0 license in a research article. It described the methods of generating synthetic land surface temperature (LST) at $30 \mathrm{~m}$ spatial resolution with 8 day intervals upon fusing 8 day composite of Moderate Resolution Imaging Spectroradiometer (MODIS)-derived LST at $1 \mathrm{~km}$ and Landsat-derived LST at $30 \mathrm{~m}$ acquired every 16 days. 


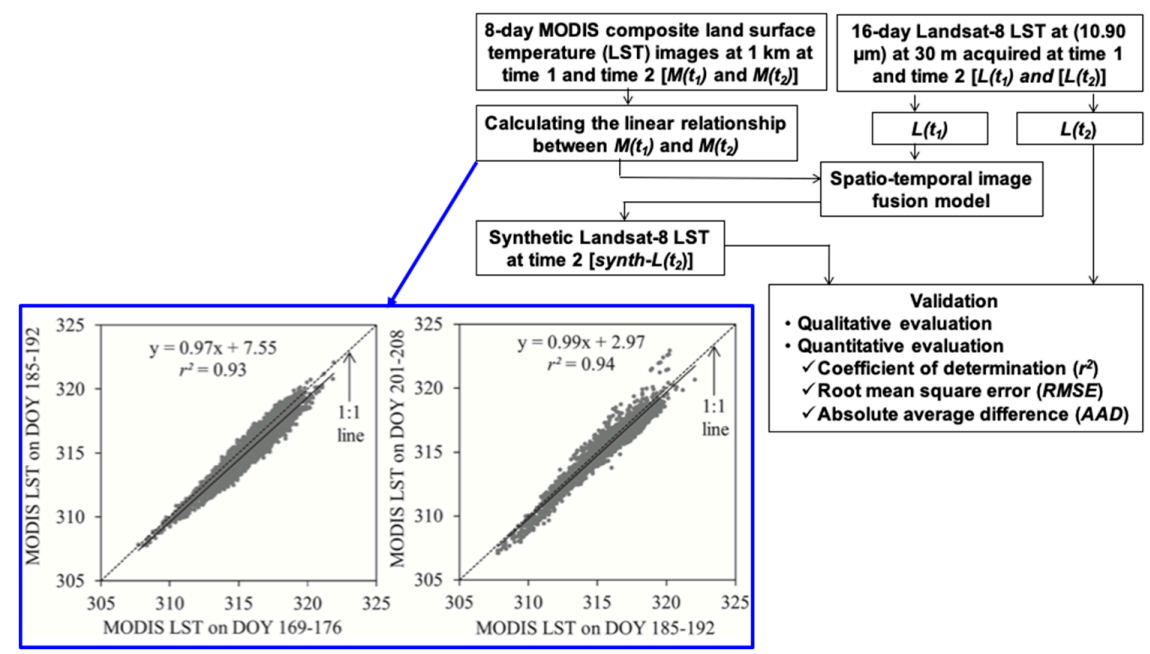

Figure 2. Example of down-scaling both of the spatial and temporal resolution of the satellite data that was "adapted from (C) Hazaymeh, \& Hassan, 2015 licensed under CC BY 4.0".

\subsubsection{Adopting/Adapting Materials from the Public Domain}

In case of developing OER materials, we often incorporated content available in the public domain, including US and Canadian government works. Note that most of the US government creative works including writing and images are not copyrighted [37]. However, such adoption/adaptation requires proper acknowledgement to the agency that has produced the work of interest [38]. In addition, it is clear that the Government of Canada permits the use of its work for non-commercial reproduction purposes [39], and such an illustration is provided in Figure 3. Note that forest occupies about 347 million hectares of Canada's landmass, which is about $9 \%$ of the global forest [40].

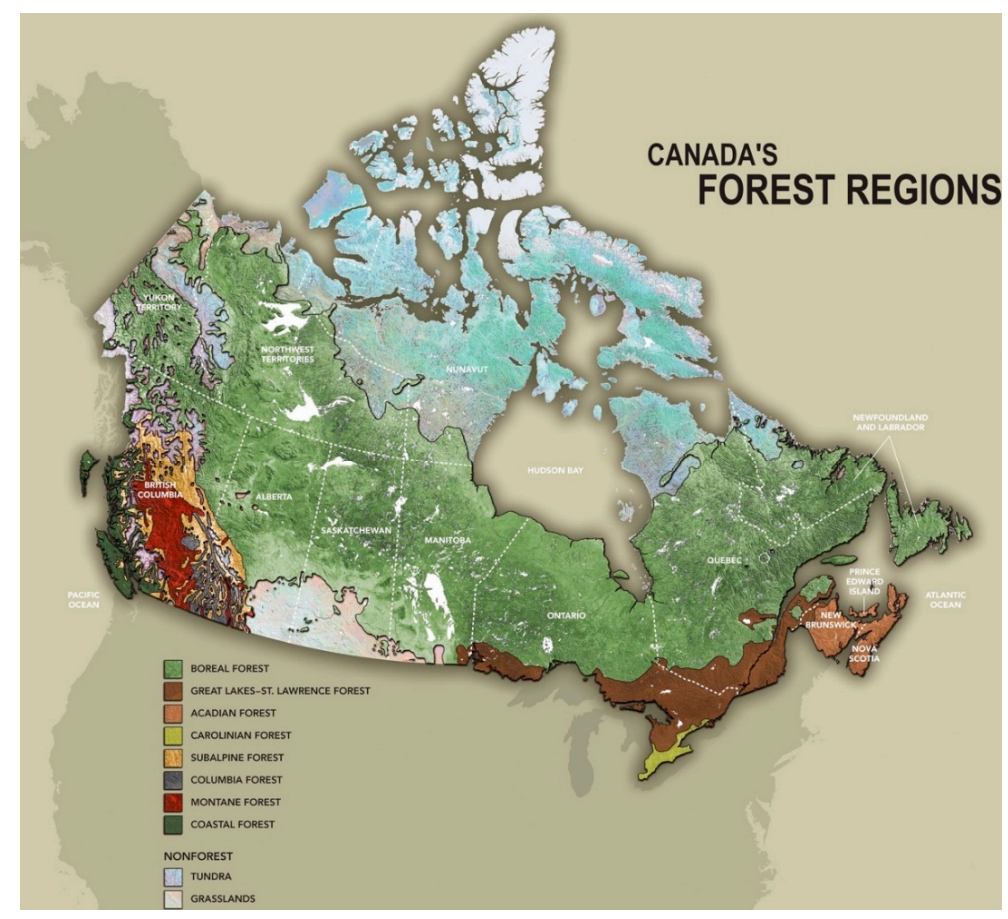

Figure 3. Canada's forest regions. Adopted from Natural Resources Canada that allows non-commercial reproduction. Such reproduction is a copy of an official work that is published by the Government of Canada, and the reproduction has not been produced in affiliation with, or with the endorsement of the Government of Canada. Available online: http://www.nrcan.gc.ca/forests/measuring-reporting/ classification/13179 (accessed on 21 February 2019) [41]. 


\subsubsection{Incorporating Authors' Own Works Published under Non-CC BY Licenses}

In general, we, as authors, transfer the copyright of an article of interest to the publisher upon its acceptance (e.g., [42]). Thus, we must seek permission from the respective publisher prior to incorporating these articles into new/adapted work. To the best of our knowledge and experience, we find that most publishers are willing to allow authors to incorporate their own transferred copyright protected materials into new ones for non-commercial purposes. Such an example is shown in Figure 4, where the first author of this manuscript was the lead author of a manuscript published by the Canadian Aeronautics and Space Institute (CASI).
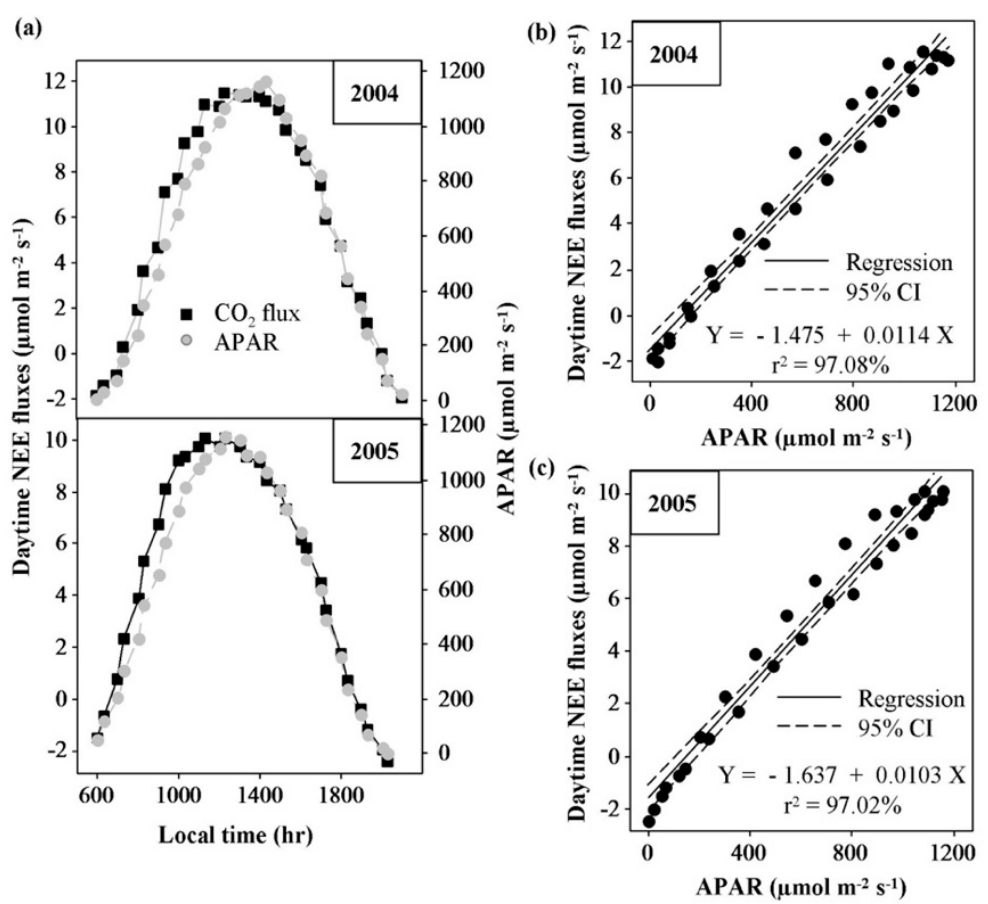

Figure 4. Relationship between absorbed photosynthetically active radiation (APAR) and daytime net ecosystem exchanges (NEE) over a balsam fir forest in New Brunswick, Canada. Panel (a) shows averaged May-September period daytime NEE as a function of local time for 2004 and 2005. Panel (b,c) illustrates linear fits applied to plots of daytime NEE as a function of APAR. Note that this graphic is "adopted from Hassan et al. [43] (C2006 CASI, where the publisher allows Hassan as an author to reproduce for non-commercial purposes".

\subsection{Analysing the Impact of the Developed OER}

We analysed the impact of the developed OER materials in four ways: (i) the potential cost savings for the students, (ii) usage statistics of the OER in the online repository, (iii) the impact on the students' learning using the University of Calgary's universal student ratings of instruction (USRI) instrument [44], and (iv) the expression of interest in adopting the materials by other universities. These are briefly described in Section 3-"Results and Discussion".

\section{Results and Discussion}

\subsection{Brief Description of the Developed OER}

We developed OER materials for the course called ENGO 583/ENEN 635 Environmental Modelling. It is a cross-listed course between geomatics engineering at a fourth year level (i.e., ENGO 583) and environmental engineering at a graduate level (ENEN 635). Figure 5 shows the screenshot of the home page of the developed OER materials available in the PRISM repository. 


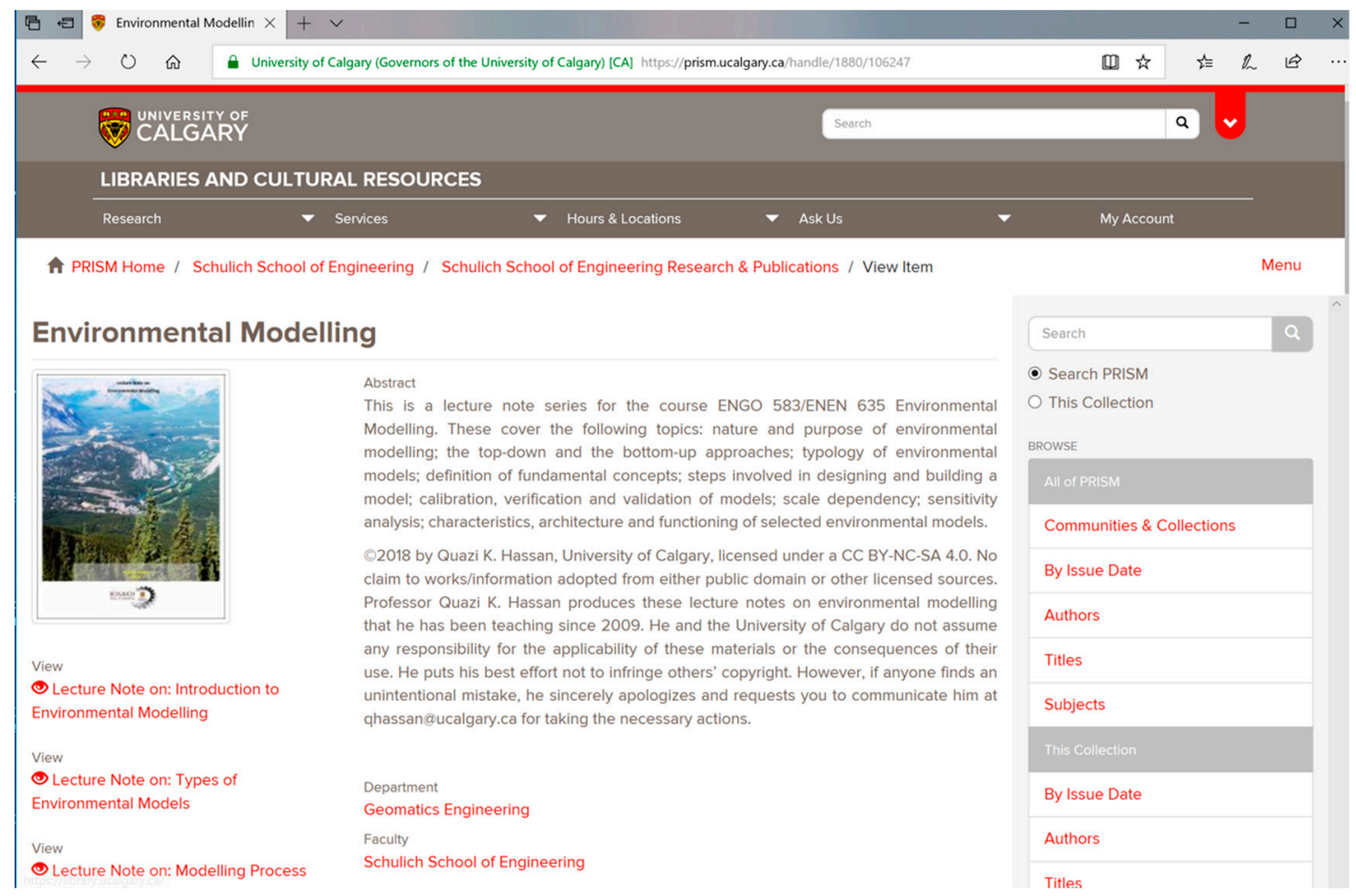

Figure 5. Home page of the developed OER (doi: http://dx.doi.org/10.11575/PRISM/5245).

The developed materials consisted of 20 Microsoft PowerPoint-based pdf files that are individually downloadable from PRISM. These materials were clustered into two broader themes or sections- "fundamentals of environmental modelling", and "modelling of environmental issues". The section "fundamentals of environmental modelling" consisted of seven lecture notes that discussed the following rudimentary concepts: (i) introduction to environmental modelling, (ii) types of environmental modelling, (iii) modelling processes, (iv) model sensitivity analysis, (v) model calibration and uncertainty analysis, (vi) model validation, and (vii) scaling issues in environmental modelling. The other section, "modelling of environmental issues", comprised 13 lecture notes that illustrated the mechanism of developing various models to discuss a set of environmental issues. These included: (i) solar radiation/energy modelling, (ii) evapotranspiration modelling, (iii) modelling the effect of greenhouse gases on temperature, (iv) wind energy modelling, (v) modelling potential species distribution, (vi) bioenergy modelling, (vii) forecasting forest fire danger conditions, (viii) modelling local warming trends, (ix) forecasting river water flow, (x) modelling vegetation phenological stages, (xi) forecasting rice yield, (xii) surface water quality modelling, and (xiii) mediated modelling.

\subsection{Potential Cost Savings for the Students}

We made our OER materials available during the winter 2018 semester, spanning between the months of January and April, and they were considered as the textbook for the students. To our knowledge, none of the students enrolled on the course bought any textbooks in addition to acquiring the generated OER materials. Consequently, we considered that every student saved at least $\$ 200$ by avoiding the purchase of textbooks. The assumption of such cost lay in the fact that a student would be required to buy at least two textbooks to cover the material delivered in the scope of the course. It is worth noting that similar findings of cost savings by students or those not keen to purchase textbooks were reported in the literature for OER materials that are available on the internet (e.g., [45,46]). 


\subsection{Usage Statistics as Observed through the Online Repository}

We acquired some quantitative data (all time usage and views/downloads in the past six months) available from the PRISM website that showed the usage and interest of the material worldwide. Since the launch of the material (i.e., January 2018), a total of 5605 downloads and 2353 views were recorded as of 22 April 2019, as shown in Figure 6. The top five countries either by downloads or by views in the past six months are also given in Figure 6 to demonstrate the education outreach of this particular OER material. In addition, these materials were found to be one of the most popular items (i.e., ranked number 7) after summing the number of file downloads and item views since the launch, as calculated on 22 April 2019 according to PRISM repository data. Thus, we assumed that the present courseware has created opportunities for potential cost savings for students and would continue to help in the learning of the general audience in this area worldwide.

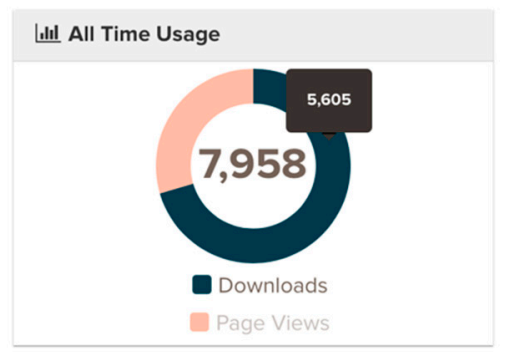

Figure 6. Global usage and interest in the developed OER, as acquired on 22 April 2019 from PRISM.

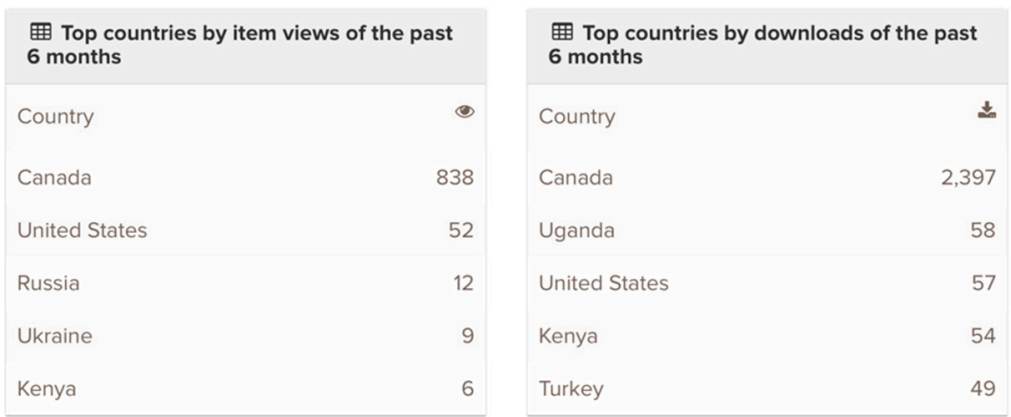

In addition, we attempted to quantify the usage of the developed materials by analyzing the students enrolled in the course ENGO 583/ENEN 635. In fact, we used these materials in winter 2018 and 2019, when there were 42 enrolled students. If we assume that each student accessed these materials twice through both downloading and viewing, then the total count would be 1680 $(=42$ (students) $* 20$ (number of lecture notes) $* 2$ (number of times accessed)). Thus, the remaining count (i.e., greater than 6000, as depicted in Figure 6) of the accessed materials might have been due to other learners across Canada and elsewhere in the world. Consequently, we could consider that the developed OER materials were able to generate considerable interest worldwide.

\subsection{Impact of the OER on the Students' Learning}

In order to assess the impact of the developed OER on the students' learning, we employed the universal student ratings of instruction (USRI) instrument, which has been in operation at the University of Calgary for at least two decades. Note that the USRI consists of 12 measures [47]; however, we analysed three of the measures, i.e., (i) content well organized; (ii) I [student] learned a lot in this course; and (iii) support materials helpful) that were related to the students' learning over the years 2014-2018. During this period, for the first three years, the course used traditional materials (which included materials extracted from non-OER sources), while we used the developed OER materials in 2018. Figure 7 shows the impact of the developed OER in comparison to the traditional materials on student learning. It revealed that the OER materials enhanced the students' learning ability in all three measures. 


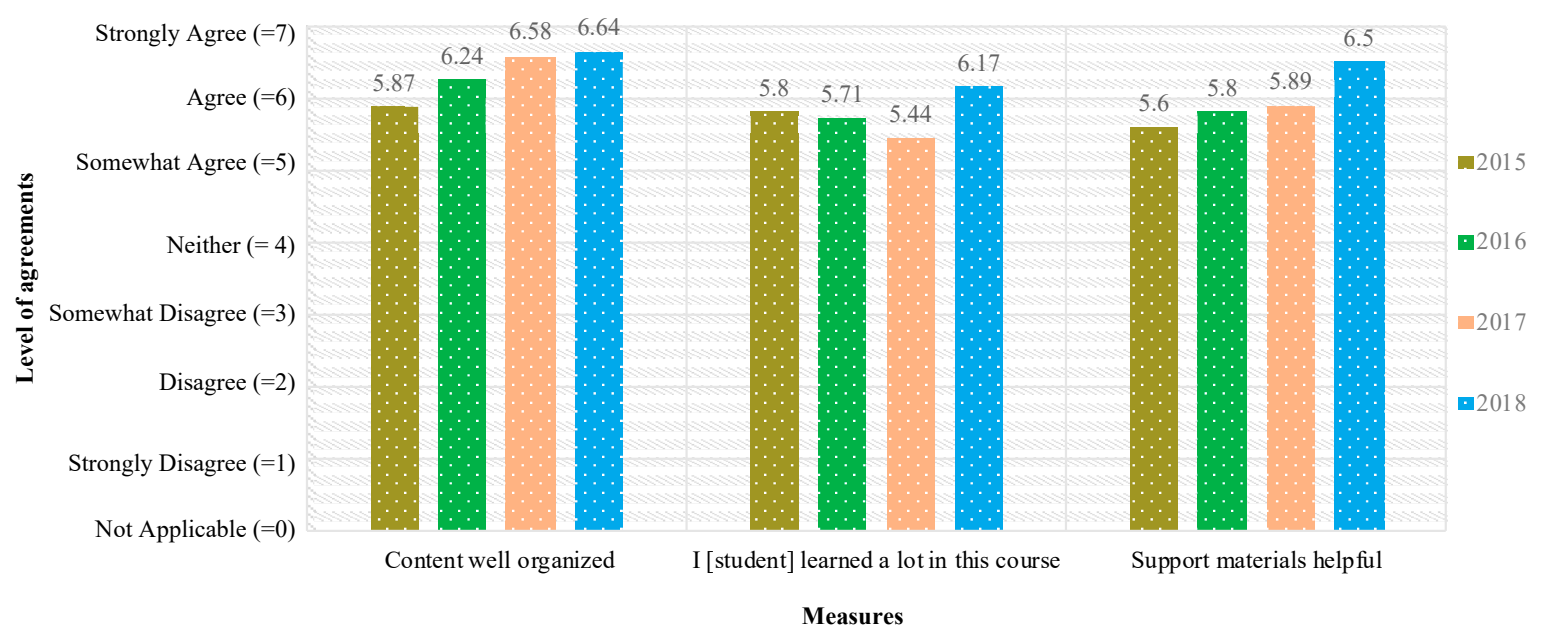

Figure 7. Impact of the developed OER on the students' learning in comparison to traditional materials analysed using some of the relevant measures acquired through the universal student ratings of instruction (USRI) instrument.

\subsection{Expression of Interest in Adopting the Materials from Other Universities}

Since the launch of these specific OER materials, we received several emails that expressed interest in adopting/adapting the generated materials, and these are summarized in Table 1. In addition, the second author of this article had already adapted some of the developed OER materials into an undergraduate course called "natural hazard modelling" at the University of Alberta. He would also like to do the same for another undergraduate course (i.e., remote sensing) in fall 2019 at the same institute.

Table 1. Higher academic institutes that showed interest in adopting/adapting our OER materials.

\begin{tabular}{|c|c|c|}
\hline Ref. & Name of the Higher Educational Institute & Comments \\
\hline [48] & $\begin{array}{l}\text { Department of Earth and Environmental } \\
\text { Sciences, Yarmouk University, Jordan. }\end{array}$ & $\begin{array}{c}\text { Interested in adopting as a graduate } \\
\text { course. }\end{array}$ \\
\hline [49] & $\begin{array}{l}\text { Department of Civil Engineering, COMSATS } \\
\text { University-Abbottabad Campus, Pakistan }\end{array}$ & $\begin{array}{c}\text { Indicated the usefulness and relevance } \\
\text { of the OER in two undergraduate } \\
\text { courses, i.e., "Geo-informatics" and } \\
\text { "Disaster Management". }\end{array}$ \\
\hline [50] & $\begin{array}{l}\text { Department of Computer Science and } \\
\text { Engineering, Khulna University of Engineering } \\
\text { and Technology, Bangladesh. }\end{array}$ & $\begin{array}{l}\text { Keen to adapt for teaching computing } \\
\text { algorithms for environments. }\end{array}$ \\
\hline [51] & BMS School of Architecture, Bangalore, India. & $\begin{array}{l}\text { Interested in adapting for courses } \\
\text { related to landscape and environment. }\end{array}$ \\
\hline [52] & $\begin{array}{l}\text { Department of Surveying and GeoInformatics, } \\
\text { Akanu Ibiam Federal Polytechnic, Nigeria. }\end{array}$ & $\begin{array}{c}\text { Sought permission to use for two } \\
\text { graduate courses, i.e., "Environmental } \\
\text { Applications of Remote Sensing" and } \\
\text { "Land Use Planning". }\end{array}$ \\
\hline
\end{tabular}

\subsection{Challenges of Developing OER}

Post-secondary institutions around the world have been using the internet and other relevant technologies to develop and distribute teaching and learning materials for decades. OER have gained critical attention from stakeholders in teaching and learning communities for their potential and promise to obviate demographic, economic, and geographic boundaries of scholarships and education to promote life-long and personalized learning. The rapid growth of OER materials certainly provides 
new opportunities for teaching and learning; however, the challenges remain evident in several areas, including but not limited to the following:

- Scholars or creators of OER materials sometimes lack knowledge in assessing the proper compatibilities of licensing and attribution while adopting, adapting, or creating OER materials without any restrictions to be utilized immediately after hosting in repositories. We have identified this as a major challenge in generating OER materials because the created documents are already distributed in diverse geographical locations;

- Often, a lack of excitement and motivation from fellow colleagues and peers do not encourage scholars to create new knowledge in OER materials, although some adoption and adaptation may be evident. Additionally, immediate rewards are not discernible if a scholar develops OER materials to support his/her courses at post-secondary institutions;

- While generating our OER materials for hosting in the PRISM repository at the UofC, we identified that knowledge of OER licensing systems and compatibility checks is lacking on campus, and we recognized the lack of financial resources that support the adaptation (in particular, graphics) and/or generation of new materials.

- We came across an interesting challenge regarding the familiarity of OER materials among the student groups within the institution where we generated the materials. As a result, we assume, if the students are not well aware of the quality of OER materials, the generated content may not bring immediate impact to the learning communities. Note that an OER advocacy group was visible on campus to encourage adopting OER materials in the learning environment at the UofC, which may not be the case at other post-secondary institutions;

- Researchers have argued that the sustainability [53] and quality [28] of OER materials remain an important issue. However, after generating the OER materials, we received appreciation (see Section 3.5- "Expression of interest in adopting the materials from other universities" for details), and institutions from diverse developing countries are adopting these materials to teach in both graduate and undergraduate courses. In this circumstance, we assume that the additional challenge of creating OER is to consider the appropriateness of the material for the learner communities and if the material is sustainable and brings positive impacts to scholarly communities.

\section{Concluding Remarks}

In the scope of this paper, we summarized the lessons learned through the development of OER course materials for the field of environmental modelling. The major obstacle we encountered was the existence of limited OER that we could either adopt or adapt. On the other hand, we found an enormous number of figures available in the public domain, from places such as the following: (i) US Governmental organizations/departments, e.g., NASA, USGS, EPA, etc.; (ii) the Government of Canada; (iii) Wikipedia; (iv) Wikimedia; and (v) Flicker. In addition, we found that it would be possible to incorporate an authors' own work published under a non-CC BY license only if it was reproduced for non-commercial purposes. In this case, we suggest that a researcher consult the publisher prior to implementing this particular idea. Moreover, we evaluated the impact of the developed OER in four ways: (i) the students enrolled in the course called ENGO 583/ENEN 635 in winter 2018 did not purchase textbooks, thus saved the associated cost; (ii) the materials were either viewed or downloaded across the world, and our materials were seen to have a rank of number 7 in terms of the sum of file downloads and item views according to PRISM as of 22 April 2019; (iii) the students learned better according to the data acquired by the University of Calgary's USRI instrument, and (iv) at least five faculty members from various countries sought permission to adopt the materials for their relevant graduate/undergraduate courses. Despite this, we identified a set of challenges, such as the following: (i) scholars/creators' lack of knowledge about the licensing issues, (ii) lack of excitement and motivation from both the academics and students, and (iii) resources, particularly financial ones, 
are quite limited in the case of generating new OER. Finally, we believe that the lessons we learned through this exercise could encourage other academics across the world to generate new OER for facilitating the improvement of the teaching and learning environment.

Author Contributions: Conceptualization, Q.K.H., K.R.R.; writing一original draft preparation, Q.K.H., K.R.R., K.Z.S., and A.D.; writing-review and editing, Q.K.H., K.R.R., K.Z.S., and A.D.; supervision, Q.K.H.

Acknowledgments: The authors would like to thank the Office of Institutional Analysis at the University of Calgary for acquiring and providing the USRI data.

Conflicts of Interest: The authors declare no conflict of interest.

\section{References}

1. Hocevar, C.; Lange, J. Challenges and Opportunities: Open Educational Resources (OERs) at McGill University; Student Society of McGill University: Montreal, QC, Canada, 2017; 73p.

2. Mossley, D.D. Open Educational Resources and Open Education; The Higher Education Academy: Heslington, UK, 2013; Available online: https://ils.unc.edu/courses/2014_fall/inls690_109/Readings/Mossely2013OERandOpenEducation.pdf (accessed on 28 March 2019).

3. Koroivulaono, T. Open educational resources: A regional university's journey. Int. J. Educ. Technol. High. Educ. 2015, 11, 1-17. [CrossRef]

4. Oldfield, J.D. An implementation of the generative learning object model in accounting. In Proceedings of the 2008 Australasian Society for Computers in Learning in Tertiary Education, Melbourne, Australia, 30 November-3 Deccember 2008; ASCILITE: Melbourne, Australia; pp. 687-695.

5. Burbaite, R.; Bespalova, K.; Damaševičus, R.; Štuikys, V. Context-Aware Generative Learning Objects for Teaching Computer Science. Int. J. Eng. Educ. 2014, 30, 929-936.

6. Štuikys, V.; Damaševičus, R. Towards knowledge-based generative learning objects. Inf. Technol. Control. 2007, 36, 202-208.

7. Boyle, T. Design principles for authoring dynamic, reusable learning objects. Australas. J. Educ. Technol. 2016, 19, 46-58. [CrossRef]

8. Ariani, Y. Developing college students' soft skills through generative learning model. Adv. Soc. Sci. Educ. Humanit. Res. 2017, 118, 830-834.

9. Oyesiku, D.; Adewumi, A.; Misra, S.; Ahuja, R.; Damaševičus, R.; Maskeliunas, R. An Educational Math Game for High School Students in Sub-Saharan Africa. Commun. Comput. Inf. Sci. 2018, 942, 228-238.

10. Raziunaite, P.; Miliunaite, A.; Maskeliunas, R.; Damasevicius, R.; Sidekerskiene, T.; Narkeviciene, B. Designing an educational music game for digital game based learning: A Lithuanian case study. In Proceedings of the 2018 41st International Convention on Information and Communication Technology, Electronics and Microelectronics, Opatija, Croatia, 21-25 May 2018; pp. 800-805.

11. Glennie, J.; Harley, K.; Butcher, N.; van Wyk, T. (Eds.) Open Educational Resources and Change in Higher Education: Reflections from Practice; Commonwealth of Learning: Vancouver, BC, Canada, 2012; 291p.

12. 2005 Program Evaluation Findings Report: MIT OpenCourseWare. Available online: https://ocw.mit.edu/ ans7870/global/05_Prog_Eval_Report_Final.pdf (accessed on 28 March 2019).

13. Giving Knowledge for Free: The Emergence of Open Educational Resources. Available online: http: //www.oecd.org/education/ceri/38654317.pdf (accessed on 28 March 2019).

14. Santos, A.; McAndrew, P.; Godwin, S. Open educational resources: New directions for technology-enhanced distance learning in the third millenium. Formamente 2008, 1-2, 111-126.

15. Picasso, V.; Phelan, L. The evolution of open access to research and data in Australian higher education. Int. J. Educ. Technol. High. Educ. 2015, 11, 122-133. [CrossRef]

16. Richter, T.; McPherson, M. Open educational resources: Education for the world? Distance Educ. 2012, 33, 201-219. [CrossRef]

17. Stacey, P. Government support for open educational resources: Policy, funding, and strategies. Int. Rev. Res. Open Distance Learn. 2013, 14, 67-80. [CrossRef]

18. Garza, L.; Sancho-Vinuesa, T.; Zermeno, M. Indicators of pedagogical quality for the design of a massive open online course for teacher learning. Int. J. Educ. Technol. High. Educ. 2015, 12, 104-118. 
19. Van Noorden, R. Science journals end open-access trial with Gates Foundation. Nature 2018, 559, 311-312. [CrossRef] [PubMed]

20. Rice University's Connexions Project Pioneers Open-Source Academic Publishing | EurekaAlert! Science News. Available online: https://www.eurekalert.org/pub_releases/2004-02/ru-ws1021904.php (accessed on 28 March 2019).

21. BCcampus OpenEd Resources-Learning about, and Experiencing, Open Educational Practices. Available online: https://open.bccampus.ca (accessed on 24 April 2019).

22. Japan Open Course Ware Consortium: A Case Study in Open Educational Resources Production and Use in Higher Education. Available online: http://www.oecd.org/education/ceri/37647892.pdf (accessed on 28 March 2019).

23. Butcher, N. Open Educational Resources and Higher Education. Available online: http://oerworkshop. weebly.com/uploads/4/1/3/4/4134458/03_open_educational_resources_and_higher_education.pdf (accessed on 28 March 2019).

24. Council of Ministers of Education, Canada. Available online: https://www.cmec.ca/299/education-in-canadaan-overview/index.html (accessed on 28 March 2019).

25. Scassa, T. Canada's New Draft Open Government Licence. Available online: http://www.teresascassa.ca/index. php?option=com_k2\&view=item\&id=113:canadas-new-draft-open-government-licence \&Itemid=83 (accessed on 28 March 2019).

26. McGreal, R.; Anderson, T.; Conrad, D. Open educational resources in Canada 2015. Int. Rev. Res. Open Distance Learn. 2015, 16, 161-175. [CrossRef]

27. Budget-Content Development-Library at University of Calgary. Available online: https://library.ucalgary. ca/c.php?g=255277\&p=3804033 (accessed on 28 March 2019).

28. Yuan, L.; Macneill, S.; Kraan, W. Open Educational Resources-Opportunities and Challenges for Higher Education. Available online: http://publications.cetis.org.uk/wp-content/uploads/2012/01/OER_Briefing Paper_CETIS.pdf (accessed on 28 March 2019).

29. Open Access Authors Fund-Scholarly Communication-Library at University of Calgary. Available online: https://ibrary.ucalgary.ca/guides/scholarlycommunication/oafund (accessed on 28 March 2019).

30. Hassan, Q.K. Environmental Modelling; University of Calgary: Calgary, AB, Canada, 2018; Available online: http://dx.doi.org/10.11575/PRISM/5245 (accessed on 28 March 2019).

31. PRISM Home. Available online: https://prism.ucalgary.ca/ (accessed on 28 March 2019).

32. Levey, L. Finding relevant OER in higher education: A personal account. In Open Educational Resources and Change in Higher Education: Reflections from Practice; Glennie, J., Harley, K., Butcher, N., van Wyk, T., Eds.; Commonwealth of Learning: Vancouver, BC, Canada, 2012; pp. 125-140.

33. De los Arcos, B.; Farrow, R.; Perryman, L.-A.; Pitt, R.; Weller, M. OER Evidence Report 2013-2014. Open Research Hub. 2014. Available online: http://oro.open.ac.uk/41866/1/oerrh-evidence-report-2014.pdf (accessed on 28 March 2019).

34. Katz, Z. Pitfalls of open licensing: An analysis of creative commons licensing. IDEA 2006, 46, 391-413.

35. Ahmed, M.R.; Rahaman, K.R.; Hassan, Q.K. Remote sensing of wildland fire-induced risk assessment at the community level. Sensors 2018, 18, 1570. [CrossRef] [PubMed]

36. Hazaymeh, K.; Hassan, Q.K. Fusion of MODIS and Landsat-8 surface temperature images: A new approach. PLoS ONE 2015, 10, e0117755. [CrossRef] [PubMed]

37. U.S. Government Works, USAGov. Available online: https://www.usa.gov/government-works (accessed on 28 March 2019).

38. NASA Image Use Policy, Precipitation Measurement Missions. Available online: https://pmm.nasa.gov/ image-use-policy (accessed on 28 March 2019).

39. Terms and Conditions, Natural Resources Canada. Available online: https://www.nrcan.gc.ca/termsconditions/10847 (accessed on 28 March 2019).

40. How Much Forest Does Canada Have? | Natural Resources Canada. Available online: https://www.nrcan.gc. ca/forests/report/area/17601 (accessed on 28 March 2019).

41. Forest Classification, Natural Resources Canada. Available online: https://www.nrcan.gc.ca/forests/ measuring-reporting/classification/13179 (accessed on 28 March 2019). 
42. American Scientific Publishers: Journal of Biobased Materials and Bioenergy-Copyright Transfer Agreement. Available online: http://www.aspbs.com/jbmbe/JBMBE\%20Copyright\%20Transfer\%20Form.pdf (accessed on 28 March 2019).

43. Hassan, Q.K.; Bourque, C.P.-A.; Meng, F.-R. Estimation of daytime net ecosystem CO2 exchange over balsam fir forests in eastern Canada: Combining averaged tower-based flux measurements with remotely sensed MODIS data. Can. J. Remote Sens. 2006, 32, 405-416. [CrossRef]

44. Universal Student Ratings of Instruction (USRI-Course Evaluation)—Office of Institutional Analysis at University of Calgary. Available online: https://www.ucalgary.ca/usri/ (accessed on 23 April 2019).

45. Bliss, T.J.; Hilton, J., III; Wiley, D.; Thanos, K. The cost and quality of online open textbooks: Perceptions of community college faculty and students. First Monday 2013, 18, 1. [CrossRef]

46. Weller, M.; de los Arcos, B.; Farrow, R.; Pitt, B.; McAndrew, P. The impact of OER on teaching and learning practice. Open Praxis 2015, 7, 351-361. [CrossRef]

47. Universal Student Ratings of Instruction (USRI-Course Evaluation)—Office of Institutional Analysis at University of Calgary. Available online: https://www.ucalgary.ca/usri/node/161 (accessed on 23 April 2019).

48. Al-Rawabdeh, A.; (Yarmouk University, Irbid, Jordan). Personal communication, 2018.

49. Akbar, T.A.; (COMSATS University- Abbottabad Campus, Abbottabad, Pakistan). Personal communication, 2018.

50. Rabbi, J.; (Khulna University of Engineering and Technology, Khulna, Bangladesh). Personal communication, 2019.

51. Cherian, R.; (BMS School of Architecture, Bengaluru, India). Personal communication, 2019.

52. Ejiaha, I.R.; (Akanu Ibiam Federal Polytechnic, Amoncha, Nigeria). Personal communication, 2019.

53. Atkins, D.E.; Brown, J.S.; Hammond, A.L. A Review of the Open Educational Resources (OER) Movement: Achievements, Challenges, and New Opportunities; A Report to The William and Flora Hewlett Foundation; 2007; 80p, Available online: https://hewlett.org/wp-content/uploads/2016/08/ReviewoftheOERMovement.pdf (accessed on 28 March 2019).

(C) 2019 by the authors. Licensee MDPI, Basel, Switzerland. This article is an open access article distributed under the terms and conditions of the Creative Commons Attribution (CC BY) license (http://creativecommons.org/licenses/by/4.0/). 